\title{
Produção textual, revisão e reescrita: uma proposta com bilhetes orientadores
}

\author{
Oscarina de Castro Silva Fontenele ${ }^{\mathrm{i}}$ \\ Pedro Rodrigues Magalhães Neto ${ }^{\text {ii }}$
}

\section{RESUMO}

Este artigo discute o ensino de produção textual, mais especificamente, a importância da revisão e da reescrita para o aprimoramento de um texto. O objetivo é analisar o desempenho em produção textual de alunos de $6^{\circ}$ ano do ensino fundamental de uma escola pública de Parnaíba-PI, quanto à realização das etapas de revisão e de reescrita. Para alcançar esse objetivo, recorremos à BNCC (BRASIL, 2017), Antunes (2003; 2010), Marcuschi (2008), Ruiz (2015), Serafini (2001), entre outros. Quanto à metodologia, trata-se de uma pesquisa de campo, de natureza descritiva, com abordagem qualitativa, na qual usamos bilhetes orientadores como estratégia de intervenção. Os resultados evidenciam o aumento do desempenho dos alunos na versão reescrita em relação aos aspectos de textualidade e aos elementos básicos do gênero textual.

Palavras-chave: Produção textual; Reescrita; Revisão; Bilhete orientador.

\begin{abstract}
This article discusses the teaching of textual production, more specifically, the importance of revision and rewriting for text improvement. The objective is to analyze the performance in textual production of 6th grade elementary school students from a public school in Parnaíba-PI, regarding the completion of the revision and rewriting steps. To achieve this goal, we turned to the BNCC (BRASIL, 2017) and to Antunes (2003; 2010), Marcuschi (2008), Ruiz (2015), Serafini (2001), among others. As for the methodology, it is a field research, with descriptive nature and a qualitative approach, in which we use guidance notes as an intervention strategy. The results show an increase in the level of students' production in the revised version in relation to aspects of textuality and the basic elements of the textual genre.
\end{abstract}

Keywords: Textual production; Rewritten; Revision; Guiding notes.

\footnotetext{
${ }^{i}$ Mestre em Letras, pela Universidade Estadual do Piauí-UESPI. Professora efetiva do Instituto Federal de Educação, Ciência e Tecnologia do Piauí - IFPI. Uruçuí, Brasil. ORCID: https://orcid.org/0000-0002-4650-8606 | profaoscarinaportugues@ gmail.com

ii Doutor em Letras Linguística pela Universidade Federal de Pernambuco - UFPE. Professor do PROFLETRAS, Programa de Pós-Graduação em Letras da Universidade Estadual do Piauí - UESPI. Teresina, Brasil.

E-mail: pedrormneto@bol.com.br
} 


\section{INTRODUÇÃO}

A escrita é uma competência cujo domínio se exige na sociedade atual, por isso, o ensino de produção textual é um tema frequente nas discussões no contexto da área de linguagem. Essa recorrência se explica, em parte, pelo baixo desempenho dos alunos nessa prática de linguagem; e, ao mesmo tempo, provavelmente, porque a produção de texto é considerada o ponto de partida e de chegada de todo o processo de ensino/aprendizagem de língua (GERALDI, 1997).

Este estudo se ajusta às recomendações da Base Nacional Comum Curricular BNCC (BRASIL, 2017, p.76), na qual as práticas de produção de texto devem levar os estudantes a "desenvolver estratégias de planejamento, revisão, edição, reescrita e avaliação de textos, tendo em vista as restrições temáticas, composicionais e estilísticas dos textos pretendidos". Nesse sentido, justifica-se a necessidade de uma reflexão sobre como realizar essas práticas de modo que essa recomendação seja atendida.

Dessa forma, este artigo propõe uma discussão teórico-prática sobre o ensino de produção textual, mais especificamente, sobre a natureza processual dessa prática de linguagem, destacando a importância da realização das etapas de revisão e de reescrita pelos alunos para o aprimoramento de um texto escrito. Sustentam nossas reflexões os estudos sobre texto, textualidade e gêneros textuais de Antunes (2003; 2010), Bakhtin (2011), Koch (2009) e Marcuschi (2008), as concepções de escrita discutidas por Koch e Elias (2015), bem como os estudos sobre revisão, reescrita e intervenção pedagógica no ensino de produção textual de Menegassi (1998), Ruiz (2015), Serafini (2001), dentre outros.

O presente texto é parte de uma pesquisa do Mestrado Profissional em Letras PROFLETRAS, da Universidade Estadual do Piauí - UESPI, realizada com alunos de $6^{\circ}$ ano do Ensino Fundamental, de uma escola pública de Parnaíba-PI. Nosso estudo partiu da seguinte questão: em que medida a realização das etapas de revisão e de reescrita pode melhorar o desempenho dos alunos em produção textual? Na busca por respostas, temos como objetivo analisar o desempenho em produção textual de alunos de $6^{\circ}$ ano do ensino fundamental quanto à realização das etapas de revisão e reescrita. Quanto à caracterização, trata-se de uma pesquisa de campo, de natureza descritiva; 
com abordagem qualitativo-interpretativa, na qual foram realizadas produções de texto, seguidas de revisão e de reescrita usando a estratégia de bilhetes orientadores.

Quanto à estruturação, este trabalho é composto por quatro partes, além desta introdução e das considerações finais. Na primeira parte, lançamos um olhar sobre o processo da escrita, analisando suas concepções e a importância dos processos de revisão e de reescrita para uma produção textual; na segunda, refletimos sobre intervenção pedagógica nos textos dos alunos por meio de bilhetes orientadores; na terceira, expomos o percurso metodológico; e, na quarta parte, analisamos versões de textos dos alunos.

\section{CONCEPÇÕES SOBRE A ESCRITA DE TEXTOS NA ESCOLA}

No contexto do processo de ensino e aprendizagem de Língua Portuguesa, pensar a escrita de textos na escola significa considerar o texto a ser produzido em suas reais condições de produção. Há mais de duas décadas, o sistema educacional brasileiro oficializou uma visão de ensino com a publicação dos Parâmetros Curriculares Nacionais - PCN (BRASIL, 1997), recentemente complementados pela Base Nacional Comum Curricular - BNCC (BRASIL, 2017), que tem como princípio "o texto como unidade básica do ensino". Todavia, de forma geral, o desempenho dos estudantes, sobretudo em produção textual, ainda é insatisfatório. Resultados oficiais, como os dados do Exame Nacional do Ensino Médio-ENEM-2019, revelam que somente 53 alunos obtiveram a nota máxima e, aproximadamente, 143 mil alunos zeraram a redação, em um universo de mais de 3,9 milhões de participantes (BRASIL, 2020).

Segundo Koch e Elias (2015), no ambiente escolar, muitas são as respostas para a pergunta "O que é a escrita?" Sob diversas perspectivas de investigações, a escrita se constitui em um produto sócio-histórico-cultural, associada ao entendimento do que seja linguagem, texto e sujeito que escreve. A compreensão dessa relação determina como praticamos e ensinamos a escrita. Segundo essas autoras, a escrita pode ser compreendida segundo três concepções, as quais têm como foco a língua, o escritor ou a interação. Na visão de escrita com foco na língua, temos a concepção de linguagem como um sistema pronto, em que o escritor se apropria de regras para bem desenvolver 
a escrita. $\mathrm{O}$ texto é um produto da codificação realizado pelo escritor a ser decodificado pelo leitor.

$\mathrm{Na}$ concepção com foco no escritor, o texto é visto como um produto do pensamento do escritor. A escrita é uma atividade por meio da qual quem escreve expressa seu pensamento, suas intenções, sem levar em conta os conhecimentos do leitor ou interação que envolve o processo da escrita (KOCH; ELIAS, 2015).

Na concepção com foco na interação, a escrita é vista como produção textual: para realizá-la, o escritor ativa conhecimentos linguísticos, enciclopédicos, interacionais e mobiliza estratégias. O autor pensa no que vai escrever considerando o seu leitor. Nessa concepção, o escritor precisa conhecer o leitor, organizar as ideias e revisar a escrita ao longo do processo. Com isso, o sentido do texto resulta da interação entre os interlocutores (KOCH; ELIAS, 2015). Nessa concepção interacional, diferente das anteriores pela interação entre escritor-leitor, tanto aquele que escreve como aquele para quem se escreve são vistos como sujeitos ativos que constroem o texto e são construídos nele.

Para Fiad e Mayrink-Sabinson (1991):

\begin{abstract}
a escrita é uma construção que se processa na interação e [...] a revisão é um momento que demonstra a vitalidade desse processo construtivo, pensamos a escrita como um trabalho de reescritas. Consideramos um texto como um momento no percurso desse trabalho, sempre possível de ser continuado. O texto original e os textos dele decorrentes podem nos dar uma dimensão do que é a linguagem e suas possibilidades. (FIAD; MAYRINK-SABINSON, 1991, p. 55)
\end{abstract}

A compreensão de "escrita como trabalho" permite ao professor planejar uma produção textual que mostre ao aluno a necessidade de selecionar, organizar, desenvolver ideias e revisar a escrita, guiada pelo objetivo da produção e pela interação que o escritor deseja estabelecer com o leitor. Trata-se de um exercício para identificar o que não está claro, o que falta, o que precisa ser modificado, pois um texto é uma construção, um processo, que envolve momentos diferentes (KOCH; ELIAS, 2015).

\title{
1.1 A natureza processual da escrita
}

$\mathrm{Na}$ perspectiva geral deste estudo, ao se falar de escrita como um processo devemos compreender como uma competência, cuja aquisição é gradativa. Seu ensino e 
aprendizagem envolvem várias etapas, dentre as quais se destacam os momentos de revisar e reescrever. Nesse sentido, Serafini (2001) afirma:

\begin{abstract}
A produção de um texto adequado resulta de um trabalho longo e difícil, que requer muito empenho [...]. Na realidade, cada texto nasce gradativamente e através de muito empenho; escrever é, na maior parte dos casos, uma profissão, um trabalho como outro qualquer, que requer técnica e esforço [...] aprender a fazer uma redação consiste em distinguir as várias fases de sua realização: planejamento, seleção e organização de ideia, desdobramento, revisão e redação final. (SERAFINI, 2001, p. 21-22)
\end{abstract}

Possenti (2005, p. 8), com ponto de vista semelhante, observa que "no processo de escrita 'no mundo', depois da primeira versão, o texto passa por sucessivas revisões". A partir das ideias desses estudiosos, fica evidente a rejeição da visão de texto como produto codificado para ser decodificado, e de texto como representação mental do escritor. Nesse sentido, é válida a defesa de que para aprender a escrever é necessário um tempo largo, utilização de muitas estratégias, sem ansiedade do produto pronto, pois esta competência precisa ser ampliada à medida que se avança nos níveis de escolaridade.

Nessa visão processual, aprendemos a escrever escrevendo muito, compartilhando com outros, escutando ideias, acrescentando, corrigindo, apagando. Por isso, conforme Passarelli (2012), há necessidade de compreender que a produção de um bom texto se condiciona a etapas que levarão a um avanço gradual na mobilização de habilidades para escrever. Aceitar isso é analisar um texto sob uma perspectiva de processo e não como um produto.

Pensamos como Antunes (2003) para quem a produção de um texto não pode ser proposta como algo que o aluno já sabe ou que já deveria saber. Devemos ter um passo a passo da escrita, para mostrar essa dinâmica. Para essa autora, existem três etapas para a escrita entendidas como "distintas e intercomplementares".

À primeira etapa - do planejamento - corresponde todo o cuidado para delimitar o tema, eleger objetivos, escolher o gênero, delimitar critério de ordenação de ideias e prever as condições dos leitores e forma linguística que o texto deve assumir.

À segunda etapa - da escrita - corresponde a tarefa de pôr no papel, de registrar o que foi planejado; é quando aquele que escreve toma as decisões de ordem lexical (escolha das palavras) e de ordem sintático-semântica (escolha das estruturas das frases) tudo em conformidade com as condições concretas da situação de comunicação;

À terceira etapa - da revisão e da reescrita - corresponde ao momento de análise do que foi escrito, para aquele que escreve confirmar se os objetivos 
formam cumpridos, se há coerência e clareza no desenvolvimento das ideias; para decidir sobre o que fica o que sai o que reformula. (ANTUNES, 2003, p.54-56)

Sem dúvida, a concepção de escrita como interação impõe esses momentos, cuja realização concorre para a construção da textualidade. Segundo Marcuschi (2008), um texto é uma atividade sistemática de atualização discursiva da língua e a textualização mostra quanto um texto é rico em seu potencial para conectar atividades sociais, conhecimentos linguísticos e conhecimentos de mundo.

\subsection{O processo de revisão}

A revisão textual tem um importante papel, pois contribui para que o aluno (re)elabore seu texto observando aspectos linguísticos, temáticos, estruturais, além de diferentes fatores contextuais. Em decorrência desse processo de reflexão, o aprendiz compreende a existência de um interlocutor e que a compreensão do seu dizer no texto demanda ajustes de informações. Compreende também que ao escrever precisamos usar as palavras de determinada forma para não comprometer a construção de sentido pelo leitor (ROCHA, 2008).

Tendo em vista o objetivo deste trabalho, a revisão é entendida como um procedimento que permite não apenas ver melhor, mas ver de outro ângulo, já que durante a produção da primeira versão do texto, o aluno se preocupa mais com o que dizer, como dizer, que palavras usar. É durante a revisão que o aluno terá possibilidade de se concentrar nas questões ligadas ao plano textual-discursivo, como dizer de outro jeito, corrigir o que foi dito, ampliar as ideias, uma forma de adequar sua comunicação com o presumido leitor (MENEAGASSI, 1998).

A revisão é uma ação que dá origem a um novo tipo de processo, permitindo uma nova fase na construção do texto, pois é a partir de revisões efetuadas no texto que surge a reescrita; portanto, a revisão é uma condição para a reescrita. Menegassi (1998) aponta três maneiras de realizar a revisão de textos em sala de aula:

\footnotetext{
a) revisão individual, em que o aluno revisa seu texto sem a interferência de outra pessoa;

b) revisão colaborativa, em que os pares se auxiliam ou até mesmo o professor, em momento de interação oral;

c) revisão orientada, em que o professor oferece sugestões de revisão ao texto do aluno de forma escrita. (MENEGASSI, 1998, p.8-9)
} 
Essas possibilidades desfazem a ideia de que a revisão do texto do aluno deve ficar a cargo do professor. A atividade de revisar pode ser feita pelo próprio aluno-autor, com seus pares colegas de sala e pelo professor coletivamente ou, como é mais comum, pelo professor via anotações no texto do aluno.

Conforme Serafini (2001), a revisão representa um passo fundamental para a produção textual. Na primeira versão, prestamos mais atenção à origem das próprias ideias, ao passo que na revisão "a atenção é posta, preferencialmente, sobre a constatação de que as ideias sejam expressas de modo organizado, claro e coerente" (SERAFINI, 2001, p.81). A autora ainda observa que o processo de revisão, quando repetido mais de uma vez, contribui para adequar significativamente o texto. A revisão pode ser desenvolvida pelo próprio autor, porém o olhar de outros sobre o texto pode ser mais eficaz. Caso a revisão seja feita pelo autor, o resultado "será melhor quanto maior for o intervalo de tempo passado entre a composição e a revisão" (SERAFINI, 2001, p.81).

Pensamos como Araújo (2004), para quem a revisão é um contínuo reelaborar forma e conteúdo; é trabalhar a linguagem da escrita. A revisão implica releituras que podem produzir marcas no texto. Nesse conjunto de ideias, é importante que o aluno entenda que a revisão, como retomada do texto, não é sinal de inexperiência ou incapacidade, mas uma necessidade inerente a qualquer produção escrita.

\subsection{0 processo da reescrita}

A palavra "reescrita", como assevera Araújo (2004), tem muitos sentidos; no contexto escolar, o mais comum é o de "passar a limpo", ação que se preocupa com a grafia, com letra bonita, folha sem rasuras, borrões. A autora admite que essa preocupação é legítima, contudo, essa dimensão da reescrita - de correção -, por ser um mero mecanismo de ajuste do texto a normas e convenções instituídas, não deve ser o foco principal nem o fim último das operações de reescrita.

Nesse mesmo entendimento, Gusmão (2015) assevera:

Consideramos a reescrita a atividade realizada pelo professor e aluno conjuntamente ou alunos e colegas em que parte da leitura da primeira versão do texto escrito para realizar um trabalho de reflexão interativa/dialógica sobre o discurso, aspectos internos e externos e a variedade padrão da língua 
e, consequentemente, a escrita de uma nova versão do texto. Essa ação implica, portanto, um trabalho de aperfeiçoamento do texto. (GUSMÃ̃), 2015, p. 106)

É evidente a importância da etapa de reescrita para que o aluno possa considerar um texto escrito não como um produto, mas como um processo, no qual seu autor percorre um caminho até chegar a sua versão final.

A realização das etapas de revisão e reescrita é recomendada em documentos oficiais como a Base Nacional Comum Curricular - BNCC que estabelece que o componente curricular de Língua Portuguesa, nas práticas de produção de texto, deve levar os estudantes a "desenvolver estratégias de planejamento, revisão, edição, reescrita e avaliação de textos, tendo em vista as restrições temáticas, composicionais e estilísticas dos textos pretendidos" (BRASIL, 2017, p.76).

A reescrita é uma operação que constitui a parte visível da atividade de revisão, que deixa marcas, rasuras, rastros das transformações do texto. A revisão e a reescrita são consideradas produtivas e etapas das estratégias da escrita. O rascunho é um recurso importante para a produção textual e para a reflexão sobre a língua em seu uso efetivo em situações de escrita (ARAÚJO, 2004).

Analisando as formas como o aluno desenvolve a reescrita, Ruiz (2015) esclarece que, ao revisar, refazer, reescrever, reelaborar, reestruturar o próprio texto, o aluno pode proceder de maneiras variadas: em geral, escreve o texto na totalidade; mas em algumas situações se limita à reescrita parcial sobreposta à original. A autora ressalta ainda que, geralmente, o modo como o aluno realiza a reescrita depende da forma como o professor elaborar os comentários e apontamentos sobre as inadequações observadas no texto do estudante.

\section{ESTRATÉGIAS DE INTERVENÇÃO E BILHETES ORIENTADORES}

Para Passarelli (2012, p. 80), “a interação professor-aluno é um aspecto determinante para a organização da situação didática". É a mediação do professor via instrumentos que fará o aluno analisar o texto devolvido com os apontamentos, os quais vão lhe mostrar a necessidade da reescrita. Nesse movimento de tomar os apontamentos 
do professor e dar a eles sua própria compreensão, o aluno estabelece um juízo de valor, que o leva ao amadurecimento no domínio da escrita. Dessa forma, professor e aluno, sujeitos da sala de aula, precisam se engajar em um processo interacional para que a prática do ensino de produção textual se transforme.

Nessa perspectiva, nas práticas inerentes ao contexto escolar, o grande benefício da intervenção do professor está em orientar o trabalho de produção textual, de maneira que leve o aluno a pensar sobre sua escrita e a tomar decisões. A intervenção é um procedimento essencial, que possibilita monitorar as dificuldades e os avanços do aluno; sem esse retorno, não podemos falar em ensino de produção textual (GASPAROTTO; MENEGASSI, 2013).

Serafini (2001) reconhece três grandes tendências de correção de texto usadas pelos professores que podem conduzir uma reescrita:

\footnotetext{
- A correção indicativa - consiste em marcar junto à margem as palavras, as frases e os períodos que apresentam algum erro ou são pouco claros. Nas correções desse tipo, o professor, frequentemente, se limita à indicação do erro e altera muito pouco; há somente correções ocasionais, geralmente, limitadas a erros localizados, como os ortográficos e lexicais.

- A correção resolutiva - consiste em corrigir todos os erros, reescrevendo palavras, frases e períodos. O professor realiza uma delicada operação que requer tempo e empenho; procura separar tudo o que é aceitável e interpreta as intenções do aluno; reescreve depois tais partes, fornecendo o texto correto.

- A correção classificatória - consiste na identificação dos erros através de uma classificação (se são de ordem sintática, de ortografia, de pontuação, dentre outras), utilizando um conjunto de símbolos - geralmente letras ou abreviaturas, que o aluno já conhece - escritos à margem do texto; essas letras funcionam como código de correção. (SERAFINI, 2001, p.113-114)
}

A análise dessas formas de intervenção no texto do aluno revela que as três têm um traço comum: preocupação com a superfície textual. Nelas, está ausente o diálogo entre professor e aluno. Nas palavras de Ruiz (2015, p. 33), a intervenção ainda "tem o objetivo de chamar atenção do aluno para os problemas do texto. A tarefa de corrigir é, assim, uma espécie de 'caça-erros'; são os 'defeitos', e não as ‘qualidades', que são focalizados".

É importante pontuar que os estudos de Serafini (2001) são citados como uma referência para a temática discutida, pois julgamos válido conhecer as práticas realizadas por muitos docentes, para poder pensar em ressignificações do trabalho com a linguagem escrita. 
Em seus estudos, Ruiz (2015, p. 47) propôs uma categoria de intervenção, que denominou de correção textual-interativa, caracterizada por comentários mais longos do que os que se fazem na margem, razão pela qual são geralmente escritos em sequência ao texto do aluno, no espaço pós-texto, na forma de pequenos "bilhetes". Esses bilhetes, em geral, têm duas funções básicas: falar acerca da revisão realizada pelo aluno e falar da correção do professor.

Para Ruiz (2015), a escrita de bilhetes textual-interativos, após o corpo textual, é um instrumento muito válido, especialmente quando desejamos apontar problemas de ordem global, relacionados ao conteúdo do texto. Os bilhetes se configuram como uma intervenção caracterizada pela "interlocução aluno-produtor/professor-corretor/alunorevisor", altamente dialógica em termos bakhtinianos. Além de apontar erros, elogia o que foi feito ou cobra o que deveria ter sido feito. Em razão de nosso objetivo, adotamos a intervenção textual-interativa no formato de bilhetes, para conduzir os alunos à revisão e à reescrita dos textos, que constituem o corpus de nossa pesquisa.

Menegassi (1998) esclarece que os bilhetes precisam, para se tornar claros e eficazes, apresentar quatro componentes básicos:

1) Apresentação do problema a ser revisado;

2) Identificação da localização do problema [...];

3) Apresentação do contexto em que se encontra o problema;

4) Oferecimento de diretrizes para a reformulação do problema levantado. (MENEGASSI, 1998, p. 200)

Diante do exposto, podemos dizer que não é simples nem rápido levar professores e alunos a considerarem a escrita como um trabalho que envolve diversos processos desde o plano mental das ideias até a versão final do texto escrito no papel; mas é preciso defender essa ideia, informar tanto ao professor que ensina, quanto ao aluno que deve aprender (GASPAROTTO; MENEGASSI, 2013).

\section{O PERCURSO METODOLÓGICO}

Considerando nosso objetivo de analisar o desempenho em produção textual de alunos de $6^{\circ}$ ano do ensino fundamental quanto à realização das etapas de revisão e reescrita, nosso estudo é uma pesquisa de natureza descritiva. Conforme a compreensão de Gil (2002, p. 42), “a pesquisa descritiva tem como objetivo primordial a descrição 
das características de determinada população ou fenômeno ou, então, o estabelecimento de relações entre variáveis".

Quanto aos procedimentos, realizamos uma pesquisa de campo, pois foi desenvolvida por meio da observação direta das atividades do grupo estudado pela professora pesquisadora em sala de aula. Quanto à análise de dados, optamos pela abordagem qualitativo-interpretativa pela possibilidade de atender às questões de estudo de sala de aula, conforme pontua Gil (2002), permitindo uma relação dinâmica de interação entre o pesquisador e sujeitos informantes que não podem ser traduzidos por meio de números.

O percurso metodológico desta pesquisa inicia a partir do contato, das observações, da vivência diária da pesquisadora-autora em uma escola pública estadual da zona urbana de Parnaíba-PI, escolhida em virtude de ser o local de trabalho da pesquisadora. Os participantes desta pesquisa são alunos de uma turma de $6^{\circ}$ ano do ensino fundamental, com faixa etária entre onze e quatorze anos, sendo dezoito meninos e dezenove meninas. Desse conjunto, nove repetiam o $6^{\circ}$ ano. Quanto às características socioeconômicas, segundo as fichas de matrícula, são crianças e adolescentes cuja maioria dos pais têm ensino fundamental; poucos concluíram o ensino médio. Grande parte desses estudantes são oriundos de bairros distantes da escola e, por isso, fazem uso de transporte escolar. Segundo informação da secretária da escola, cinquenta por cento dos alunos recebem benefício do Programa Bolsa Família.

A coleta de dados é, conforme Marconi e Lakatos (2003, p. 165), a "etapa da pesquisa em que se inicia a aplicação dos instrumentos elaborados e das técnicas selecionadas, a fim de se efetuar a coleta dos dados previstos”. Nesse sentido, realizamos duas atividades diagnósticas: 1- produção textual de um conto maravilhoso (duas versões: inicial e reescrita); 2 - produção textual de relato pessoal (duas versões: inicial e reescrita); estas produções foram realizadas a partir de propostas apresentadas no livro didático dos alunos.

A escolha desses gêneros encontra justificativa, principalmente, por constarem no livro didático dos alunos; dessa forma, não haveria acréscimo de conteúdo, nem gasto com material. Além disso, nesses gêneros, predomina a sequência narrativa. $\mathrm{O}$ conto é uma narrativa ficcional com elementos fabulosos, aborda assuntos relacionados à família, mostra valores como respeito, humildade, persistência, bondade, temas tão 
necessários ao convívio social. Já o relato pessoal é uma narrativa não ficcional, que tem como finalidade o relato, oral ou escrito, de experiências vivenciadas, marcantes na vida de quem o escreve, situadas predominantemente no tempo da memória. A linguagem, em geral, é espontânea e informal.

O desenvolvimento das atividades ocorreu entre os meses de abril a agosto de 2018, em um total de vinte aulas de cinquenta minutos cada, em dias e horários regulares da disciplina Língua Portuguesa.

\subsection{As produções textuais}

As atividades de produção textual foram antecedidas por atividades de leitura e estudo do texto: interpretação, compreensão e linguagem do gênero, apresentadas nessa sequência na unidade de estudo do livro didático dos alunos. Essas atividades diagnósticas, inclusive as versões de cada gênero, não foram realizadas de forma seguida. Foram intercaladas por estudos gramaticais, avaliações, leituras extras.

Cada produção foi realizada em duas etapas, que corresponderam às duas versões de cada gênero; o primeiro texto produzido foi o conto maravilhoso. Os alunos, como solicitado, fizeram um rascunho do que iam escrever, depois, fizeram uma revisão individual; em seguida, passaram a limpo o texto, que foi recebido pela professora. Assim, tínhamos a versão inicial do conto, para ser lida e realizar o processo de intervenção, encerrando-se, dessa forma, a primeira parte da produção textual.

De posse da versão inicial dos contos, procedemos à leitura e, em um primeiro contato, notamos as dificuldades dos alunos com a escrita; a sucessão dos fatos narrados seguiam um contínuo próximo da oralidade, com presença mínima de pontuação. Por isso, além da intervenção do tipo textual-interativo, por meio dos bilhetes escritos com orientações e sugestões, fizemos indicações no corpo dos textos, acerca de pontuação nos diálogos, paragrafação e uso de letras maiúscula.

Realizados esses instrumentos, os textos com os bilhetes foram devolvidos aos alunos, que foram orientados a ler os bilhetes com bastante atenção, reler o próprio texto e observar as indicações, para depois reescrever o conto.

É interessante relatar a reação dos alunos ao receberem os textos com os bilhetes em anexo. Demonstraram surpresa com o conteúdo do bilhete, tiraram dúvidas; a 
pergunta mais frequente foi se era para fazer de novo o texto. Ao final dessa interação, tínhamos a versão reescrita, concluindo, desse modo, a segunda parte da produção do conto.

Em relação à produção para obtenção da versão inicial e versão reescrita do relato pessoal, seguimos as mesmas etapas e procedimentos realizados na produção do conto.

As atividades diagnósticas foram dirigidas aos 37 alunos da turma, mas nem todos realizaram as atividades, porque faltaram nos dias das aplicações ou, mesmo estando presentes, não fizeram. Por isso, adotamos como critério para seleção dos textos a comporem o corpus de análise, o aluno ter realizado, integralmente, as duas atividades diagnósticas, incluindo as duas versões das produções textuais de cada gênero. Como critério complementar, havia a necessidade de o aluno e o responsável terem concordado em participar da pesquisa e assinando os Termos de Assentimento e de Consentimento Livre e Esclarecido - TCLE, respectivamente. Ao final, 10 alunos atenderam aos critérios, cada um com 4 versões, totalizando 40 textos.

\subsection{Procedimentos para as análises}

Orientados pelo objetivo geral da pesquisa, elegemos para a análise das produções três categorias: 1- aspectos de textualidade: coesão, coerência; 2- os elementos básicos do gênero textual: conteúdo temático, estrutura e estilo; 3- realização das sugestões do professor.

A escolha dessas categorias se justifica, primeiro, porque entendemos, conforme Antunes (2010), que fazer da textualidade objeto de ensino (e/ou de estudo) é assumir a textualidade como princípio que manifesta e regula as atividades de linguagem, pois todo enunciado apresenta uma conformidade textual. Em segundo lugar, uma proposta de ensino baseada em gêneros textuais e seus elementos básicos possibilita ao professor observar e avaliar as capacidades de linguagem dos alunos, permitindo-lhe uma visão objetiva para uma intervenção didática (DOLZ; SCHNEUWLY, 2004). Além disso, consideramos necessário investigar se o aluno, quando provocado, estabelece uma interlocução, já que o diálogo entre professor e aluno por meio do texto é uma condição fundamental no processo de produção textual. 
As produções foram digitadas, reproduzindo fielmente a escrita dos alunos. São apresentadas por pares de versões com o bilhete orientador. Analisamos primeiro as versões do conto maravilhoso, seguidas das versões do relato pessoal. Para garantir o anonimato das produções, a identificação foi feita pela letra A (aluno) seguida por um número, por exemplo: A1: Versão inicial e A1: Versão reescrita; A2: Versão inicial e A2: Versão reescrita; e assim sucessivamente. De modo semelhante, identificamos as versões do relato pessoal.

Neste artigo, recorte da dissertação, reproduzimos a análise das versões iniciais e reescritas de dois alunos (A2) e (A1), selecionados por serem representativos do desempenho observado no corpus da pesquisa.

\section{ANALISANDO OS TEXTOS DOS ALUNOS}

Quanto aos aspectos de textualidade, à luz de Antunes (2010), Koch (2009) e Marcuschi (2008), investigamos a coesão e a coerência. A coesão diz respeito "aos modos e recursos de ligação, de encadeamento, entre os vários segmentos (palavras, orações, períodos, parágrafos) do texto" (ANTUNES, 2010, p. 35). As unidades linguísticas que marcam operações de conexão e de segmentação na superfície textual são os organizadores textuais (conjunções, articuladores e sinais de pontuação).

A coerência é, segundo Koch (2009, p. 49), "resultante de uma construção feita pelos interlocutores, numa situação de interação dada, pela atuação conjunta de uma série de fatores de ordem cognitiva, situacional e sociocultural”. A autora ainda explica que a coerência não está no texto, mas é construída a partir dele, levando-se em conta os recursos coesivos presentes na superfície textual, que funcionam como pistas ou chaves que orientam o leitor na construção de sentido. Segundo Marcuschi (2008), a coerência é um princípio interpretativo e não uma propriedade imanente ao texto. Quando entendemos um texto, oral ou escrito, é porque conseguimos atribuir coerência a esse texto, isto é, ativamos conhecimentos que veiculam sentidos ao texto.

Para a análise dos elementos básicos do gênero, tomamos por base Bakhtin (2011), que aponta o conteúdo temático, o estilo e sua construção composicional. O conteúdo temático corresponde ao que é ou pode tornar-se dizível por meio do gênero; a construção composicional é a estrutura particular dos textos pertencentes ao gênero; e o 
estilo são as configurações específicas das unidades de linguagem derivadas, sobretudo, da posição enunciativa do locutor; conjuntos particulares de sequências que compõem o texto.

Quanto à realização das sugestões do professor, baseamo-nos em Menegassi (1998), para quem existem cinco possibilidades: a) aceitar a sugestão do professor; b) aceitar a sugestão e reformular parcialmente; c) aceitar a sugestão e ir além, fazendo reformulações além das sugeridas; d) apresentar reformulações além das sugeridas; e) não aceitar as sugestões, ignorando-as ou não as acatar por não conseguir entender o sugerido ou por não conseguir reformular seu texto.

\subsection{Análise das versões do conto maravilhoso}

Para melhor compreensão, reproduzimos, a seguir (figura 01), a proposta de produção do livro didático.

Figura 1: Proposta de produção textual do conto maravilhoso

\section{AGORA É A Sua vez}

Há, a seguir, três propostas de produção de textos. Conforme a orientação de seu professor, produza os contos maravilhosos individualmente ou em grupo. Eles serão publicados depois em um livro de contos que fará parte da mostra Histórias de hoje e sempre, proposta no capítulo Intervalo.

1. Reúna-se com seus colegas de grupo para, juntos, planejarem e escreverem um conto maravilhoso. Vocês podem produzir dois tipos de conto:

- Uma história tradicional, ocorrida no passado, com as tipicas personagens de contos maravilhosos.

- Uma história ocorrida nos dias atuais. Nesse caso, trabalhem com outros tipos de personagem, como, por exemplo, um garoto corajoso e destemido, uma mocinha distraída que adora ler, um cantor de rap, um esqueitista, uma avó moderna... ou um herói às avessas, isto é, atrapalhado, que tem medo das bara-

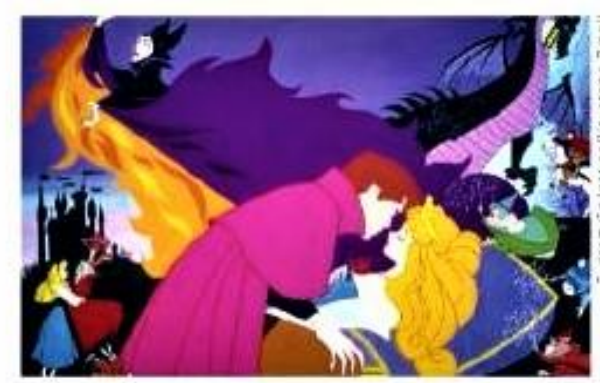
tas, etc. E, para ser o vilâo, escolham um feiticeira muito má, uma bruxa moderna, que substituiu a vassoura por uma moto aquática, etc.

2. Escolha uma personagem de conto maravilhoso de que você goste muito (um mágico, uma fada, um super-herói, etc.) e crie uma história em que ela se envolva com outras personagens de contos maravilhosos, como, por exemplo, príncipes, princesas, reis, bruxas, ogros, gigantes, dragōes, gênios, etc. Siga as instruçōes da proposta anterior.

3. Dê asas à imaginação e crie livremente um conto maravilhoso.

Fonte: Cereja e Magalhães (2015, p. 21) 
A seguir, analisamos um par de versões do conto maravilhoso, do aluno 2 (A2) à luz das categorias de análise. Para melhor compreensão das análises, transcrevemos também o bilhete orientador.

Quadro 1: A2 - Versão inicial

$\underline{\text { Uma linda filha }}$

\begin{tabular}{|c|c|}
\hline 1 & Era uma vez uma moça que teve uma filha linda \\
\hline 2 & o nome dessa moça era Raquel e da menina era \\
\hline 3 & la elas tinham uma vizinha bruxa muito invejosa \\
\hline 4 & pois queria uma filha linda como Pérola mas \\
\hline 5 & não tinha. Certo dia a bruxa resolve prender Raquel na \\
\hline 6 & mais alta torre e a forçar Raquel em ter uma linda filha \\
\hline 7 & como Pérola. Os anos se passam e ela continua pre- \\
\hline 8 & Raquel faz de tudo para \\
\hline 9 & sair daquela prisão e derrepente descobre \\
\hline 10 & relógio é magico, quando \\
\hline 11 & um gênio da lampada. $\mathrm{E}$ assim fez os três pedidos \\
\hline 12 & primeiro foi que ela tivesse um \\
\hline 13 & seu lugar, $\mathrm{o}$ segundo foi que a clone tivesse um bebê. \\
\hline 14 & e $\quad$ o terceiro foi comida para o clone e $\mathrm{o}$ bebê, assim \\
\hline 15 & desapereceu o gênio, e ela se esqueceu de \\
\hline 16 & escada e chave. \\
\hline 17 & se passaram \\
\hline 18 & mais um daqueles \\
\hline 19 & tinha um relógio má- \\
\hline 20 & e seu desejo tinha sido que \\
\hline 21 & assim foi. Quando \\
\hline 22 & mas ainda faltavam-lhe dois \\
\hline 23 & desejos que mesma \\
\hline 24 & e que a bruxa ficasse \\
\hline 25 & vida de uma menina linda, \\
\hline 26 & riam uma \\
\hline
\end{tabular}




\begin{tabular}{|l|ccccccccc|}
\hline 27 & & No & fim & tudo & deu & certo & e & a festa & foi demais, \\
\hline 28 & a & bruxa & teve & Raquel & como & madrinha & de & sua & filha \\
\hline 29 & e & todos & viveram felizes para & sempre. & & \\
\hline
\end{tabular}

Fonte: Pesquisa direta, 2018, A2.

A versão inicial do A2 mostra que ele escolheu o primeiro tipo da opção 1 da proposta e que conseguiu elaborar um texto com um nível de organização regular muito próximo de bom. Existe a presença de muitas palavras coesivas, como pronomes: "que" (linha 01), “ele/ela/elas" (linhas 03, 07, 12, 15, 18) em referências ou substituições para evitar repetições das mesmas palavras. As conjunções: "pois", "mas" (linha 04), “quando" (linha 10), “que" (linha 19), "se" (linha 25), entre outras, revelam o conhecimento do A2 em estabelecer relações de explicação, de oposição, de tempo, de condição entre as frases e períodos, recursos que, segundo Marcuschi (2008, p. 99), "constituem os padrões formais para transmitir conhecimento e sentidos".

A produção apresenta-se lógica, embora notemos uma frase incompleta (linha 18); é coerente com a temática do gênero proposto. Estruturado em três parágrafos, o conto tem as circunstâncias temporais estabelecidas por expressões como "Era uma vez” (linha 01), “Certo dia” (linha 05), “Os anos se passam” (linha 07), "No fim” (linha 27).

Reproduzimos a intervenção via bilhete.

A2,

Bom conto, parabéns! Você pode deixá-lo mais interessante.

Reproduza a fala dos personagens em forma de diálogo.

Escreva mais detalhes. Como era o castelo?

Descreva as personagens.

O leitor precisa imaginar as personagens, suas ações.

O $1^{\circ}$ parágrafo reúne ideias que podem ser separadas em mais parágrafos. No $2^{\circ}$ parágrafo, linha 18 , a frase está incompleta.

Revise e reescreva!

Profa. ......15/04/2018.

Quadro 2: A2 - Versão reescrita

$\underline{\text { Uma linda filha }}$

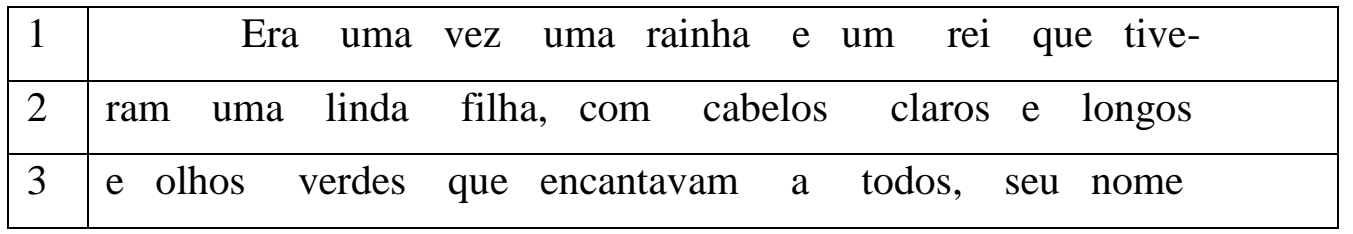




\begin{tabular}{|c|c|}
\hline 4 & Pérola Rayane e seus pais eram Pedro e Raquel \\
\hline 5 & bruxa muito invejo- \\
\hline 6 & uma filha como Pérola e não tinha \\
\hline 7 & Certo dia pensa em prender Raquel e força-la \\
\hline 8 & ter uma filha para ela, e \\
\hline 9 & Escolhe a torre mais alta \\
\hline 10 & que ninguém \\
\hline 11 & Raquel não \\
\hline 12 & saudade já toma \\
\hline 13 & No mesmo dia \\
\hline 14 & sagem dentro da parede da torre, sem saida, \\
\hline 15 & encontra \\
\hline 16 & um espelho mágico para falar com sua \\
\hline 17 & e também pede dois clones reais, uma dela e do bebê, \\
\hline 18 & acaba esquecendo uma chave e uma \\
\hline 19 & para fugir daquele lugar \\
\hline 20 & Mais tarde aparece-lhe outro gênio \\
\hline 21 & encaminhado por Pérola e diz: \\
\hline 22 & 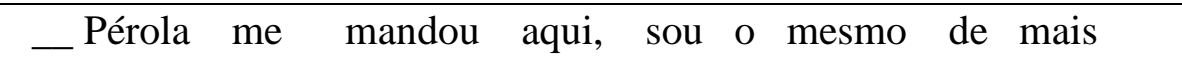 \\
\hline 23 & cedo! Os desejos de sua filha foram que você \\
\hline 24 & fosse solta e que a bruxa se tornasse \\
\hline 25 & o ultimo é seu! \\
\hline 26 & A rainha pede: \\
\hline 27 & _- Que a Bruxa tenha uma linda filha \\
\hline 28 & nunca mais mecher com \\
\hline 29 & ninguém, se isso acontecer darei uma \\
\hline 30 & festa a todos! $\mathrm{E}$ a festa aconteceu $\mathrm{e}$ todos vive- \\
\hline 31 & ram felizes para todo o sempre! \\
\hline
\end{tabular}

Fonte: Pesquisa direta, 2018, A2.

A versão reescrita do A2 apresenta um aprimoramento, o que permite caracterizá-la como uma produção muito boa. Em relação à primeira categoria - 
Aspectos de textualidade: coesão, coerência - o conto do A2 revela articulação coesiva satisfatória, uma continuidade lógica, evidenciadas por uma precisão expressiva, uma organização e uma linguagem elaborada, como exemplifica a reescrita da situação inicial do conto, "Era uma vez uma moça que teve uma filha linda o nome dessa moça era Raquel e da menina era Pérola" (versão inicial, linhas 01 e 02), "Era uma vez uma rainha e um rei que tiveram uma linda filha, com cabelos claros e longos e olhos verdes que encantavam a todos, seu nome era Pérola Rayane e seus pais eram Pedro e Raquel" (versão reescrita, linhas 01 a 04). Em outras passagens do texto, encontramos muitos outros recursos de coesão referencial como "ela" (linha 05), "força-la" (linha 07), “daquele" (linha 19) e de coesão sequencial como "pois" (linha 06), introduzindo uma explicação para a inveja da vizinha; "e" (linhas 06 e 17), estabelecendo a ideia de adição entre termos e entre orações; "para que" (linha 09), expressando a finalidade da ação da bruxa; "mas" (linha 14), estabelecendo contraste; "se" (linha 29), introduzindo a condição para realizar a festa que finaliza o conto.

O texto se mostra coerente; como se espera em uma sequência narrativa, apresenta a situação inicial, desenvolvimento, o final feliz, a presença de personagens que inspiram bondade, perdão, com presença do mágico "lâmpada mágica", "espelho mágico" (linhas 15 e 16) que vai ao encontro do conhecimento de mundo do leitor sobre contos maravilhosos.

A segunda categoria de análise - Os elementos básicos do gênero textual: conteúdo, estrutura e estilo - o A2, ao reescrever, intensifica o conteúdo fantástico, os personagens reis, rainhas, princesa, o conflito entre heroína bondosa e a bruxa invejosa, elementos característicos desse gênero textual. Quanto à estrutura, o conto apresenta sete parágrafos (na versão inicial eram três) que evidenciam a sequência narrativa básica: situação inicial, transformação e situação final. $\mathrm{O}$ discurso direto é introduzido por meio do diálogo entre o gênio e a rainha; as falas dos personagens são reproduzidas, em sua espontaneidade, aproximando personagens e leitor. As escolhas linguísticas do A2, ao longo do texto, revelam uma escrita bem ao estilo de adolescente sonhador; um narrador que observa e conta uma história em que a felicidade está não no casamento, mas na transformação do mal em bem. 
Em relação à realização das sugestões do professor, ao reescrever o texto, o A2 atendeu a todas as sugestões e fez outras reformulações, por exemplo, alterou o objeto mágico.

Considerando a análise das duas versões, notamos que a segunda é um texto bom em relação à versão inicial; a produção reescrita mostra que o A2 compreendeu as características do gênero pedido e conseguiu produzir um texto escrito com conteúdo temático, estrutura, estilo da linguagem, unidade de sentido característicos do gênero proposto.

\subsection{Análise das versões do relato pessoal}

Para melhor compreensão reproduzimos a seguir (figura 02) a proposta de produção textual do relato pessoal do livro didático.

Figura 2: Proposta de produção textual do Relato Pessoal

\section{AGORA É A SUa vez}

Escolha uma das propostas de produção de texto a seguir e escreva você também um relato pessoal. Depois, seu relato poderá ser publicado em um livro ou em um blog, conforme as orientaçóes apresentadas no capitulo Intervalo desta unidade.

1. Quem sou eu? - Você pode começar o relato dizendo seu nome e sua idade e descrevendo como você é fisicamente: cor dos olhos, do cabelo, sua altura e seu peso, seus traços particulares, com quem da familia você se parece. Conte sobre sua família: como sāo seus pais, quantos irmãos tem, se são mais velhos ou mais novos do que você, como eles são, como é o relacionamento entre vocês, etc. Você pode falar também sobre seus gostos: livros, revistas, músicas, esportes, games, filmes, programas de televisāo, pratos prediletos, passeios, hobbies, etc., sobre coisas que detesta, quais são suas manias, coisas e atitudes que lhe agradam ou que the desagradam, o que o(a) encanta no mundo e na natureza, quais sảo seus sonhos, suas vontades.

2. No túnel do tempo-Procure em sua casa uma fotografia em que vocè, bem criança, esteja em algum lugar com outras pessoas, familiares, colegas de escola ou amigos. Observe-a com atenção e embarque no túnel do tempo: inspirando-se nela, relate o que vocé $e$ as pessoas retratadas faziam naquele momento, de que evento participavam, o que falavam, do que riam, o que acontecia, etc. Para tornar seu relato mais real, peça informaçōes a seus pais sobre o que acontecia no momento em que a fotografia foi tirada.

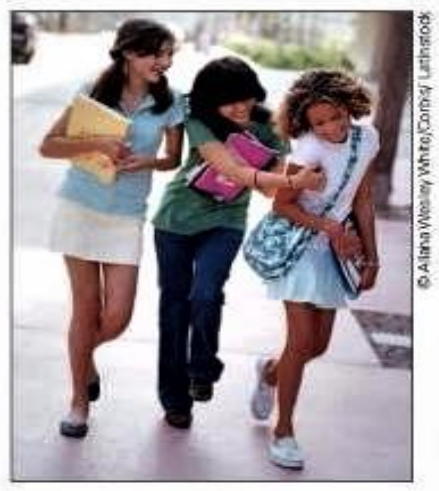

Fonte: Cereja e Magalhães (2015, p. 146-147). 
A seguir, analisamos um par de versões do relato pessoal, do aluno 1 (A1) à luz das categorias de análise. Para melhor compreensão das análises, transcrevemos também o bilhete orientador.

Quadro 3: A1 - Versão inicial

Como eu sou

\begin{tabular}{|c|c|}
\hline 1 & Meu nome é $* * * * * * *$ eu tenho 14 anos eu sou \\
\hline 2 & gordo. Tenho olhos castanhos eu tenho o cabelo preto. minha \\
\hline 3 & $\begin{array}{llllllll}\text { autura } & \text { e } 1,73 & \text { eu peso } 61 & \text { quilos. Meus traços particulares }\end{array}$ \\
\hline 4 & é a minha Barriga. eu pareço um pouco com o meu pai. \\
\hline 5 & os meus pais são calmos e legais, eu Tenho um irmão \\
\hline 6 & mais velho eu e o meu irmão sidamos muito bem. \\
\hline 7 & Eu e a minha familia \\
\hline 8 & no interior aconteceu \\
\hline 9 & mordida pela uma \\
\hline 10 & preucupados mais não era nada \\
\hline
\end{tabular}

Fonte: Pesquisa direta, 2018, A1.

A observação da versão inicial do A1 mostra que ele começou seu relato com um parágrafo autodescritivo, evidenciando ter entendido a primeira parte da proposta. No segundo parágrafo, inicia uma narrativa, apresenta uma contextualização de um momento marcante vivido com sua família, contudo não desenvolve o relato, não dá continuidade às ações, que são insuficientes para responder, satisfatoriamente, às perguntas: quem? o quê? quando? onde? como? por quê? de forma a caracterizar um relato pessoal.

Quanto aos aspectos de coesão e coerência textuais, o aluno, no primeiro parágrafo, escreve orações seguidas, citando suas características, algumas ligadas pela conjunção "e"; repete o pronome sujeito "eu"; faz uma retomada da palavra "interior" (linha 07) com o advérbio "lá" (linha 08), mas repete o referente "interior" revelando não saber a função (de substituição) dessa palavra como mecanismo de coesão referencial. Além disso, substitui "avó" pelo pronome "ela" (linha 09); da mesma 
forma, retoma o termo "eu e minha família" pelo pronome "Todos" (linha 09). A produção inicial do A1 em relação ao gênero solicitado é insuficiente, já que não apresenta contextualização, desenvolvimento das ações, marcas de temporalidade, não revela sensações, sentimentos provocados pela experiência, características de um relato pessoal.

Reproduzimos a intervenção via bilhete.

A1,

Você precisa desenvolver mais seu relato.

A proposta era escrever um relato de um momento marcante de sua vida.

Pode começar falando de você, de seus gostos, de sua família, mas depois precisa relatar uma história vivida.

No $2^{\circ}$ parágrafo, você começou a relatar uma história, mas parou, continue. Diga onde, quando, como, por que aconteceu o fato.

Que interior? De quem? Quem estava lá?

Tenho certeza que pode relatar um fato bem interessante!

Revise e reescreva!

Profa $10 / 08 / 2018$.

Quadro 4: A1 - Versão reescrita

\section{Como eu sou}

\begin{tabular}{|c|c|}
\hline 1 & Meu nome é $* * * * *$ eu tenho 14 anos \\
\hline 2 & meio gordo. Tenho olhos castanhos eu tenho cabelo \\
\hline 3 & Preto minha autura é 1,73 eu Peso 61 quilos. Meus \\
\hline 4 & traços particulares é a minha barriga. $\quad$ Eu pareço \\
\hline 5 & um pouco com o meu pai. os meus pais são cal- \\
\hline 6 & mos e legais, eu tenho um irmão mais velho eu \\
\hline 7 & e $\quad$ o meu irmão eu e $\mathrm{o}$ meu irmão sidamos muito \\
\hline 8 & bem. \\
\hline 9 & $\mathrm{Nu}$ certo dia no ano de 2014 \\
\hline 10 & versario na minha casa. Teve muitas brincadeiras \\
\hline 11 & e muita comida. Mais so que aconteceu um acidente com \\
\hline 12 & a minha tia querida Tia $* * * * *$ ela veio de fortaleza. ela \\
\hline 13 & Tem olhos castanhos e muito bunita. Ela si machucou \\
\hline 14 & quando tava ajudando a minha mãe $* * * * *$. \\
\hline
\end{tabular}




\begin{tabular}{|c|c|}
\hline 15 & Tou o DeDo com uma faca bem amolada. \\
\hline 16 & A minha mãe correu para ajudar minha querida \\
\hline 17 & Tia $* * * * *$ Todos ficaram preucupados com a minha \\
\hline 18 & O dedo Dela não tava sangrando muito \\
\hline 19 & a minha Tia disse que \\
\hline 20 & 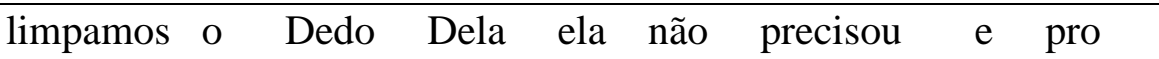 \\
\hline 21 & medico ficou tudo bem. \\
\hline
\end{tabular}

Fonte: Pesquisa direta, 2018, A1.

A versão reescrita do A1 é um texto com ideias melhor distribuídas, constituído por três parágrafos, que fornecem ao leitor informações sobre o que aconteceu "numa festa de aniversário", a "tia querida" do narrador-personagem "corta o dedo com uma faca bem amolada". As perguntas: quem? o quê? quando? onde? como? por quê? podem ser respondidas depois de uma leitura da versão reescrita. A relação de continuidade estabelecida entre as partes do texto auxilia o leitor a seguir o relato do aluno, que mostram a presença dos aspectos de textualidade: coesão, coerência. A continuidade (coesão referencial) mantém a temática e notamos o uso de mecanismos coesivos, como a substituição pronominal. Na versão reescrita, o A1 emprega cinco vezes "ela" em referência à tia; usa "todos" para retomar os membros da família implicitamente presentes na festa; operações básicas de substituições para evitar repetições. $\mathrm{O}$ aluno estabelece a relação de oposição entre o momento feliz do aniversário e o acidente "teve muitas brincadeiras e muita comida. Mais (mas) so que aconteceu um acidente" (linha 11).

Quanto à segunda categoria de análise - Os elementos básicos do gênero textual: conteúdo, estrutura e estilo - o texto reescrito reúne as características de um relato pessoal, pois é um registro de fatos vividos pelo aluno, um momento de comemoração em família, marcante em razão do acidente com a tia. Quanto à estrutura, o relato apresenta, no segundo parágrafo, a contextualização inicial "num certo dia do ano de 2014 teve meu aniversário na minha casa” (linhas 09-10). A organização possibilita que o relator seja identificado como sujeito das experiências apresentadas. As ações encontram-se organizadas em um eixo temporal claro "aconteceu um acidente com minha querida tia" (linhas 11 e 12); "ela cortou o dedo com uma faca bem amolada" (linhas 14 e 15). O aluno encerra o relato sem fazer uma apreciação geral sobre a 
experiência, como se espera de um relato pessoal. O leitor encontra respostas para as perguntas quem? o quê? quando? onde? como? por quê?

As escolhas linguísticas confirmam o estilo de um relato pessoal: narrativa não ficcional em primeira pessoa do singular, com narrador-personagem "meu nome é..." (linha 01), "na minha casa" (linha 10); verbos no passado "Num certo dia do ano de 2014 Teve o meu aniversário" (linha 09); “todos ficaram preucupados" (linha 17), "não precisou e pro medico ficou tudo bem" (linhas 20 e 21); discurso indireto no qual o narrador fala pelos personagens, fazendo uso de verbos de elocução como em "minha tia disse que não era nada" (linha 19). A linguagem é pessoal, subjetiva, revela as impressões do narrador-personagem acerca dos acontecimentos "todos ficaram preucupados" (linha 17).

Em relação à realização das sugestões do professor, o A1 atendeu às sugestões e alterou, inclusive, o conteúdo do relato; na versão inicial falava de um interior e o acidente era com a avó. Ao reescrever, desenvolveu um relato sobre um acidente doméstico com uma "tia querida". Ao reorganizar sua narrativa, dando-lhe outros personagens, enriquecendo com adjetivação "querida tia *****. Ela tem olhos castanhos e muito bunita" (linha 12 e 13), percebemos que o aluno dá indícios de sua compreensão de que a escrita é um trabalho e que "a linguagem é uma forma de interação, mais do que possibilitar uma transmissão de informações de um emissor a um receptor, a linguagem é vista como lugar de interação humana" (GERALDI, 2012, p. 41).

Ao analisar as duas versões, podemos afirmar que a versão reescrita é um texto com mais marcas da posição do autor, bem como aspectos da estrutura, conteúdo, estilo e nível de linguagem esperados do gênero pretendido. São evidências de que o A1 revisou sua produção e fez alterações em níveis variados, desenvolveu a habilidade de fazer e de refazer seu texto.

A dinâmica de ler, observar e comparar os textos para compreender a evolução dos alunos em relação à escrita nos remete ao momento da coleta de dados, cuja maior dificuldade, de modo geral, foi a pequena disposição dos alunos para produzir textos escritos. Serafini (2001) afirma que o professor deve estar predisposto a aceitar o texto do aluno, ter uma postura receptiva, aceitando sem preconceitos suas ideias, sem, 
contudo, deixar de intervir. A intervenção deve estimular o aluno a melhorar, levando em conta sua capacidade.

Avaliamos que a atitude responsiva dos alunos aos comandos dos bilhetes, ou além deles, é um indício de reflexão acerca de sua produção e de sua linguagem. Nesse sentido, as diferentes mudanças nas versões revelam que a revisão, ação necessária para a etapa da reescrita, passa a ser entendida pelos alunos como inerente ao processo de escrita. Ademais, sinaliza certo entendimento de que o "texto é um evento sócio comunicativo, que ganha existência dentro de um processo interacional. Todo texto é resultado de uma coprodução entre interlocutores" (KOCH e ELIAS, 2015, p.13).

Para nós, essa constatação é importante, porque pode nortear e ampliar o trabalho a ser desenvolvido, para que as aulas de produção textual sejam planejadas de forma que potencialize a ideia de que a produção textual é uma atividade interativa e discursiva, ou seja, trata-se de "dizer alguma coisa a alguém, de uma determinada forma, num determinado contexto histórico e em determinadas circunstâncias de interlocução" (BRASIL, 1998, p. 20-21).

\section{CONSIDERAÇÕES FINAIS}

No presente estudo, propomos uma discussão teórico-prática sobre o ensino de produção textual, destacando a relevância de oportunizar aos alunos os momentos de revisão e reescrita por meio da estratégia de bilhetes orientadores. Acreditamos que de nada adianta o professor planejar uma aula de produção textual, evidenciando as características do gênero, as condições de produção, as leituras prévias, se não incluir atividades de intervenção, com vistas ao desenvolvimento da competência da escrita.

Os alunos, quando solicitados, realizam as atividades de revisão e reescrita de seus textos. Nessa perspectiva, na análise comparativa dessas produções, constatamos que as versões iniciais revelaram, em sua maioria, uma insuficiência quanto a fatores de textualidade, bem como a aspectos da estrutura, conteúdo temático e estilo da linguagem do gênero pretendido; ao passo que as versões reescritas apresentaram um nível maior de adequação em relação aos mesmos aspectos. Assim, concluímos que o desempenho dos alunos em produção textual melhora com as etapas de revisão e reescrita realizadas a partir de uma intervenção, que evidencie aspectos de textualidade 
e os elementos básicos do gênero produzido; consideramos ainda que a intervenção textual-interativa, via bilhetes, favorece a realização das sugestões do professor pelos alunos. Observamos que os bilhetes orientadores, escritos conforme recomendam Ruiz (2015) e Menegassi (1998), contribuem para o aluno refletir sobre sua escrita, aumentam sua autonomia como escritor, pois, por meio deles, os professores podem apontar questões discursivas, indo além de inadequações ortográficas.

Dessa forma, se o objetivo da escola é ensinar o aluno a interagir pela linguagem, a produção textual deve ocupar um espaço maior nas aulas e, mais do que isso, é necessário reconhecer a importância das atividades de revisão e reescrita para o ensino sistemático de produção textual escrita, respeitando a natureza processual inerente a essa prática de linguagem.

A maior evidência resultante deste trabalho é que uma didática de ensino de produção textual deve considerar o aluno em processo de aprendizagem, por isso a intervenção docente deve ter como objetivo ensinar a escrita e não avaliar o produto. Relacionado a isso, compreendemos também que promover a revisão e a reescrita não é só mandar "passar a limpo" o texto ou caprichar a letra; essas etapas, como reiteradamente dissemos ao longo deste estudo, são momentos de volta ao texto, possibilidades de rasurar, substituir, desprezar, acrescentar práticas por meio das quais os alunos se apropriam, progressivamente, das habilidades necessárias para se tornarem escritores competentes. A leitura que o professor faz do texto do aluno deve gerar devolutivas objetivas e motivadoras, a exemplo dos bilhetes orientadores.

Por fim, defendemos que, para enfrentar o desafio de aprender a escrever, a escrita deve se tornar um hábito, uma prática corrente para os alunos, como forma de interagir, de se comunicar nas diversas situações sociais, que, diferentemente da forma oral, segue certos padrões e exige um trabalho de planejamento das palavras.

\section{Referências}

ANTUNES, Irandé. Aula de português - encontro e interação. São Paulo: Parábola, 2003.

Análises de textos: fundamentos e práticas. São Paulo: Parábola, 2010. 
ARAÚJO, Liane Castro. Reescrevendo a escrita na escola: a prática de revisão e reescrita textual mediada por pares. Dissertação de mestrado - Universidade Federal da Bahia, 2004. 207 f. Disponível em:

http://www.repositorio.ufba.br:8080/ri/bitstream/ri/11829/1/Liane\%20Araujo\%20parte \%201.pdf. Acesso em 28 jun. 2018.

BAKHTIN, Mikhail. Estética da criação verbal. 2. ed. São Paulo: Martins Fontes, 2011.

BRASIL, Ministério da Educação. Parâmetros curriculares nacionais. Terceiro e quarto ciclos $\left(5^{\mathrm{a}}\right.$ a $8^{\mathrm{a}}$ séries $)$ do ensino fundamental: língua portuguesa, SEF-MECBrasília: 1998.

, Ministério da Educação. Base Nacional Comum Curricular-BNCC. Ensino Fundamental. SEF-MEC-Brasília: 2017.

MEC. Maior índice de participação em 10 anos; custo com processo foi menor do que em 2018. Instituto Nacional de Estudos e Pesquisas Educacionais Anísio Teixeira (Inep). 2020. Disponível em http://portal.inep.gov.br/artigo/-/asset_publisher/B4AQV9zFY7Bv/content/maiorindice-de-participacao-em-10-anos-custo-com-processo-foi-menor-do-que-em2018/21206. Acesso em 24 fev. 2021.

CEREJA, William Roberto; MAGALHÃES, Thereza Cochar. Português: Linguagens. $6^{\circ}$ ano: $9^{a}$. ed. reform. São Paulo: Saraiva, 2015.

DOLZ, J.; SCHNEUWLY Bernard. Gêneros orais e escritos na escola. Campinas, São Paulo: Mercado das Letras, 2004.

FIAD, R. S.; MAYRINK-SABINSON, M. L. T. A escrita como trabalho. In: MARTINS M. H. (Org.). Questões de linguagem.4. ed. São Paulo: Contexto, 1991, p. 54-63.

GASPAROTTO, D. M.; MENEGASSI, R. J. A mediação do professor na revisão e reescrita de textos de aluno de ensino médio. Calidoscópio, São Leopoldo, v. 11, n. 1, p. 29-43, 2013.

GERALDI, J. W. Portos de passagem. 2. ed. São Paulo: Martins Fontes, 1997. O texto na sala de aula. 3. ed. São Paulo: Ática, 2012.

GIL, Antônio Carlos. Como elaborar projetos de pesquisa. 4. ed. Atlas, São Paulo, 2002.

GUSMÃO, M. A. P. A (re) escrita de textos: a prática pedagógica da professora Maria. Vitória da Conquista: Edições UESB, 2015. Disponível em: :〈https://repositorio.ufrn.br/jspui/bitstream/123456789/14294/1/MariaAPG_TESE.pdf $>$ .Acesso em: 30 jun. 2017. Acesso em 28 jun. 2018. 
KOCH, I. G. V. Introdução à linguística textual: trajetória e grandes temas. 2. ed. São Paulo: Martins Fontes, 2009.

KOCH, I. G. V.; ELIAS, V. M. Escrita e interação. In: Ler e escrever: estratégias de produção textual. 2 ed. São Paulo: Contexto, 2015. p. 31-52.

MARCONI, Marina de Andrade; LAKATOS, Eva Maria. Fundamentos de metodologia científica. 5. ed. rev. São Paulo: Atlas, 2003.

MARCUSCHI, Luiz Antonio. Produção textual, análise de gênero e compreensão. São Paulo: Parábola, 2008.

MENEGASSI, R. J. Da revisão à reescrita: operações e níveis linguísticos na construção do texto. Tese, Faculdade de Ciências e Letras de Assis, Universidade Estadual Paulista, Assis, 1998. Disponível em: <https://www.leffa.pro.br/tela4/Textos/Textos/Teses/renilson_menegassi.pdf >. Acesso em: 20 jun. 2017. Acesso em 28 jun. 2018.

PASSARELLI, Lílian Ghiuro. Ensino e correção na produção de textos escolares. São Paulo: Telos, 2012.

POSSENTI, Sírio. Aprender a escrever (re) rescrevendo. Linguagem e letramento em foco. Ministério da Educação - Cefiel /IEL/Unicamp. 2005.

ROCHA, Gladys. O papel da revisão na apropriação de habilidades textuais pela criança. In: VAL, M. da Graça Costa; ROCHA, Gladys (orgs.) Reflexões sobre práticas escolares de produção textual: o sujeito autor. 1 ed. Belo Horizonte, Autêntica/ CEALE/ FaE/UFMG, 2008, p. 69-83.

RUIZ, Eliana. Como se corrige redação na escola. São Paulo: Contexto, 2015.

SERAFINI, Maria Teresa. Como escrever textos. Trad. de Maria Augusta Bastos de Mattos. 11 ed. São Paulo: Globo, 2001. 